\title{
Atış Performanslarının Ergonomik Test Analizleri ile Tahmini
}

\section{Prediction Of Shooting Performances with Ergonomic Test Analysis}

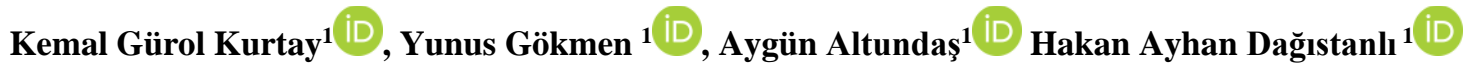 \\ ${ }^{1}$ Milli Savunma Üniversitesi Kara Harp Okulu Dekanlı̆̆ Endüstri ve Sistem Mühendisliği Bölüm Başkanlı̆̆l, O6530 Ankara, TÜRKIYE
}

Başvuru/Received: 01/10/2021Ｋabul/Accepted: 30/12/2021ＣCevrimiçi Basım/Published Online: 31/12/2021 Son Versiyon/Final Version: 31/12/2021

\begin{abstract}
$\ddot{O} z$
$\mathrm{Bu}$ çalışmada, atıcıların başarılı atış yapmalarının sağlanması ve müsabakalardaki puanlarının arttırılmasına yönelik iki farklı deneyden elde edilen sonuçların atış başarısı üzerindeki etkileri incelenmiştir. Amaç, atıııların sahip olduğu özelliklere göre atışa olan elverişliliklerinin yapılan bu testler ile belirlenmesidir. İlk deney, Auto Scoring Mirror Tracer ekipmanıyla yapılmıştır. Bu deney tek el ile yapılan ve atıcının bir hedefi aynadaki yansımasından görerek çizmeye çalıştığı bir deneydir. İkinci deney, Two Arm Coordination Test ekipmanıyla düzenlenmiştir. Bu deneyde ise atıcı iki el ile koordineli bir şekilde hedefi direkt olarak görerek çizmeye çalışmıştır. Uygulanan bu iki deneydeki amaç testi en kısa sürede ve en az hata ile tamamlamaktır. Yapılan iki deney 55 farklı atıcıya uygulanmış ve deneyi tamamlama süreleri ile hata sayıları kayıt altına alınmıştır. Deneyi tamamlayan kişilere her deney sonrası farklı kategorilerde atış yaptırılmış ve yaptıkları atış kayıtları not edilmiştir. Bu çalışmada deneyleri en az hatayla ve en kısa sürede tamamlayan atıcıların, silahlarını hedeflerinde daha başarılı bir şekilde sabit tutacağı ve diğer atıcı rakiplerine göre daha başarılı atışlar yapacağı düşünülmüştür. Bu düşüncenin ortaya konması için deneylerden elde edilen sonuçlar ile atıcıların atış başarıları arasındaki ilişki lojistik regresyon analizi ile incelenmiştir. Elde edilen sonuçlar ergonomik test skorları ile atış başarılarının doğru tahminlenebileceğini göstermiştir. Ergonomi testlerinin atış performanslarını artırmak için antrenman amaçlı yararlanılabileceği ayrıca atıcı seçiminde de bir değerlendirme kriteri olarak kullanılabileceği önerilmektedir.
\end{abstract}

\section{Anahtar Kelimeler \\ "Ergonomi, Atıclllk, Başarıll Atış Skoru, Lojistik Regresyon"}

\begin{abstract}
In this study, the effects of the results obtained from two different experiments to ensure successful shooting of shooters and to increase their scores in competitions on shooting success were examined. The aim is to determine the shooting suitability of the shooters according to their characteristics with these tests. The first experiment was done with Auto Scoring Mirror Tracer equipment. This experiment is designed in a one-handed fashion where the shooter tries to draw a target by seeing its reflection in the mirror. The second experiment was set up with the Two Arm Coordination Test equipment. In this experiment, the shooter tried to draw the target directly by seeing it in coordination with both hands. The purpose of these two designed experiments is to complete the test as soon as possible and with the least error. The two designed experiments were applied to 55 different shooters and the completion times and completion errors were recorded. The people who completed the experiment were shot and their shooting records were noted. In this study, it was thought that the shooters who completed the experiments with the least error and in the shortest time would keep their guns more successfully on their targets and shoot more successfully than other shooters. In order to demonstrate this idea, the results obtained from the experiments and the shooting success of the shooters and the relationship between them were examined by logistic regression analysis. The results obtained showed that shooting successes could be predicted correctly with ergonomic test scores. It is suggested that ergonomics tests can be used for training purposes to increase shooting performances and can also be used as an evaluation criterion in the selection of shooters.
\end{abstract}

Key Words

"Ergonomics, Shooting, Successful Shooting Score, Logistic Regression" 


\section{Giriş}

Atış, hedef olarak belirlenen noktaya bir merminin bir silahla firlatılma eylemi olarak tanımlanabilir (Ball, Best and Wrigley 2003). Atıcılık sporu, yarışmacıların yatarak, ayakta veya diz çökerek; atış tekniklerini kullanıp belirlenen süre içinde sabit ya da hareketli hedefleri mümkün olduğunca merkezden vurması gereken bir spor dalıdır. Atıcıların atış pozisyonlarına göre kullandığı teknikler farklılık göstermektedir. Atıcıların, diz çökerek yaptıkları atışlarda pozisyonlarının belirlenmesinde sağ veya sol ellerini kullanmaları önemli bir etkendir. Sağ elini kullananlar sağ dizinin, sol elini kullananlar ise sol dizinin üzerine çökerek atış yapmaktadır. Sporcunun kullandığı ilk teknik olan yatarak atışta, silahın herhangi bir obje ile temas halinde olmamasına dikkat edilmektedir. Başlıca 2 türü vardır. Bunlar, serbest silahlarla sabit hedefe atış ve av silahlarıyla hareketli hedefe atıştır.

Farklı araştırmacılarca atıcılık sporunun kökeni avcılık ile ilişkilendirilmektedir. Başlangıçta ok atma, mızrak firlatma gibi silahlarla yapılan atıcılık bir spor olarak ilk defa 10. Yüzyılda İsviçre'de yapılmıştır (Kaya, 1999). 13. ve 14. yüzyıllarda Almanya'da atıcılık kulüpleri kurulmuş ve atıcılık faaliyetleri icra edilmiştir. Atıcıllğın tam bir spor haline gelmesi ise silah sektöründeki gelişmeler ile birlikte 16. yüzyılda olmuştur. 1700'lü yıllarda Amerika'da yaygınlaşmaya başlayan atıcılık sporuna olan ilgi 1890'larda özel silahların geliştirilmesi ile artmıştır. Çok farklı silahlar ile yapılabilen bu spor dalı artan ilgi ile beraber ilk defa 1896 yılında Olimpiyat programına dâhil edilmiştir. Türkiye'de ise atıcılık, 1910 yılından sonra ilgi görmeye başlamış, spor kulüplerinin yeni yeni kurulması ve ordunun ilgi göstermesi sayesinde ilk atıcılarımız yetiştirilmeye başlanmıştır. 1937 yılında Atıcılık Federasyonu kurulmuş ve Türkiye'nin Dünya Şampiyonalarına ilk kez katılımı ise 1947 yılında olmuştur (Gilmore,1976).

Olimpiyatlarda da müsabakaların yapılmasıyla beraber daha profesyonel bir hal alan atıcılık sporunda, atıcıların seçiminde ve eğitiminde farklı metotlar uygulanarak atıcıların iyi atış yapmalarındaki faktörler belirlenmeye çalışılmışıı. Bu faktörler belirlenirken, sporcuların fiziksel, psikolojik, biyolojik vb. birçok özelliği göz önüne alınarak farklı çalışmalar yapılmıştır.

$\mathrm{Bu}$ çalışmada, atıcıların başarılı atış yapmalarının sağlanması ve müsabakalardaki puanlarının arttırılmasına yönelik iki farklı ergonomik deneyden elde edilen sonuçların atış başarısı üzerindeki etkileri incelenmiştir. Bu iki deney birbirinden yapılış açısından farklı, amaç ve kapsam bakımından ise benzerlik göstermektedir. Deneylerin ikisi de zamana ve yapılan hata sayısına göre gözlemlenmiş̧ir.

Çalışmanın amacı, atıcıların sahip olduğu özelliklere göre atışa olan elverişliliklerinin yapılan ergonomik testler ile belirlenmesi ve yeni atıcıların seçimi ile eğitiminde kullanılabilecek yeni bir yaklaşım ortaya koymaktır. Bu sayede, yeni atıcılar belirlenirken ergonomik testlerde gösterdikleri performansa göre değerlendirme yapılabilecektir. Hali hazırdaki sporcuların eğitimi için ise ergonomi testleri ile yapılan antrenmanlar sayesinde sporcuların atış müsabakalarında yaptıkları atıcılık sporu ile ilgili, çift eli koordine bir şekilde kullanabilme, titreme, kabza kavrama gibi hataların en aza indirgenmesi beklenmektedir.

\section{Literatür Taraması}

Yapılan literatür taramasında atıcılık ve nişancılık ile ilgili ergonomik çalışmalara yer verilmiştir.

Kayıhan ve arkadaşları tarafından 2013 yılında yapılan çalışmada polislerin fiziksel ve fizyolojik parametreleri ile tabanca atış etkinlikleri arasındaki ilişsi incelenmiştir. 237 erkek ile yapılan çalışmada 10 metre mesafeden tabanca atışı ve bu atışlardan aldıkları skorlar değerlendirilmiştir. Bu atı̧̧lardaki başarı durumlarına göre atıcıların bilek çevresi, biseps çevresi gibi fizyolojik özellikleri arasındaki ilişkilere bakılarak anlamlılıkları değerlendirilmiştir. Çalışmanın sonuçlarının atıcılık becerilerinin önemli olduğu polis ve sporcuların seçimi ile atış eğitimlerinde yol gösterici olacağı değerlendirilmiştir (Kayıhan vd., 2013).

Morelli ve arkadaşları tarafından 2014 yılında yapılan çalışmada geri tepme ölçümü ve silah tasarımının nişancılık performansına etkisi üzerine durulmuştur. Çalışmada iki amaç bulunmaktadır. Bunlardan ilki küçük silahların geri tepmesinin nasıl ölçüldüğü ve geri tepme etkisini en aza indirgemek için tasarımlarda geliştirilebilecek noktalara değinmektir. İkinci amaç ise atışlar sonucunda ortaya çıkan performansın nasıl iyileştirileceğini araştırmaktır. Elde edilen bulgulara göre silah tasarımı ve performans iyileştirmeye yönelik önerilerde bulunulmuştur (Morelli vd., 2014).

Carbone ve arkadaşları tarafından 2014 yılında yapılan çalışmada taktik polis memurlarının nişancılık becerilerine yük taşımanın etkisi, pilot bir çalışma ile ele alınmıştır. 6 taktik harekat polisinin nişancılık performansları yüksüz ve yüklü olarak 6 metrelik mesafeye atı̧̧ ile ölçülmüş̧ür. Çalışmadaki atış verileri incelendiğinde yakın mesafede tabanca atışının yük taşıma durumundan etkilenmediği, nişancıların başarısını azaltmadığı sonucuna varılmıştır (Carbone vd., 2014).

Erdoğan ve arkadaşları tarafından 2016 yılında yapılan çalışmada 17 üniversite öğrencisi ile el kavrama kuvveti ile atış performansları arasında ilişki olup olmadığına dair bir inceleme yapılmıştır. Bu incelemeyi yapabilmek için el dinamometresi testi uygulanmıştır. Yapılan testler sonucunda kadın öğrencilerde el kuvveti ile atış puanı arasında dominant bir ilişki olduğu, erkek öğrencilerde ise çok zayıf ve anlamsız seviyede ilişki olduğu saptanmıştır (Erdoğan vd., 2016).

Landman, Nieuwenhuys ve Oudejans tarafından 2016 yılında yapılan çalışmada kişilik özelliklerinin ve mesleki deneyimin polis memurlarının baskı altındaki atış performanslarına etkisi üzerine bir çalışma yapılmışıtır. Tümü erkek personelden oluşan bir tutuklama birimi ile çalışılmıştır. İlk aşamada personelin kişilik özellikleri ve deneyimleri belirlenmiş daha sonra ise düşük ve yüksek basınç ortamında, kaygı durumunda, hareket hızları ve bakış davranışları dikkate alınarak ölçümler yapılmıştır. Sonuç 
olarak deneyimin, kaygı ve performansı çok güçlü şekilde etkilediği, heyecan ve özdenetim kişilik özelliklerinin ise daha az oranda da olsa etkisinin olduğu görülmüştür (Landman, Nieuwenhuys ve Oudejans, 2016).

Landman, Nieuwenhuys ve Oudejans tarafından 2016 yılında yapılan çalışmada karar ile ilgili eylemlerin polislerin baskı altında atış performansına etkisi üzerine inceleme yapılmıştır. Çalışmada yüksek baskının, kaygı durumu, atış davranışı ve atış performansı üzerindeki olumsuz etki durumu test edilmiş̧ir. 42 memur üzerinden kalp atış hızı, atışs süresi ve atış başarısı için tahminler ve kontroller gerçekleştirilmiştir. Sonuç olarak polislerin eylemlerine bakıldığında yüksek baskı altında yapılan atışların başarısı önemli ölçüde doğru tahmin edilmiştir (Landman, Nieuwenhuys ve Oudejans, 2016).

Sivrikaya, Aydın ve Dumangöz tarafından 2017 yılında yapılan çalışmada 117 kişilik sporcu grubu ile çalışılmıştır. Çalışma ile çoklu zeka örnekleri; cinsiyet, yaş ve silah türüne göre karşılaştırılmıştır. İstatistiksel analizler neticesinde erkek ve kadın sporcular için Mantıksal, Matematiksel ve Kişilerarası Sosyal Zekâ arasındaki farklılıklar anlamlı olarak tespit edilirken cinsiyet faktörü göz ardı edilerek silah türüne göre yapılan incelemelerde İç Zeka ve Sözel Dilsel özellikler arasında anlamlı farklılık görülmüsştür. Yaş kriterinde ise herhangi bir anlamlılık gözlenmemiştir (Sivrikaya, Aydın ve Dumangöz, 2017).

Tenan, LaFiandra ve Ortega tarafindan 2017 yılında yapılan çalışmada askerlerin yürüyüş mesafesi, sırt çantası yükleri ve kalp atış hızlarının nişancılık üzerine etkisi araştırılmıştır. Çalışmada 12 erkek asker ormanlık arazide 12 kilometrelik mesafede yürüyüş̧ gerçekleştirmiştir. Askerler yürüyüş öncesi, ortası ve sonrasında atış görevi gerçekleştirmiştir. Sonuçta sırt çantası yükü, kalp atış hızı ve yürüyüş mesafesi arasında üçlü bir etkileşim görülmüştür. Yürüyüşs sonrası kalp atış hızları, hedefi vurma olasıllğını olumsuz etkilemiştir. Sırt çantası yükü etkileri ise tutarsız olarak belirlenmiştir (Tenan, LaFiandra ve Ortega, 2017).

Thomas ve arkadaşları tarafından 2018 yılında yapılan çalışmada özel silah ve taktik ekip üyelerinde, yük taşımanın atış poligonunda taktik performansa etkisi üzerinde durulmuştur. 12 erkek yetişmiş personel, yüklü ve yüksüz olarak atış poligonunda simüle testler gerçekleş̧irmiş ve bu testleri tamamlama zamanları kayıt altına alınmıştır. Yüklü ve yüksüz yaptıkları atış performansları ile test tamamlama zamanları istatistiksel analize tabi tutulmuş ve elde edilen sonuçlar ile yorgunluğun performans üzerindeki olumsuz etkisi gösterilmiş̧ir (Thomas vd., 2018).

Aydın, Arıkan ve Revan tarafından 2019 yılında yapılan çalışmada 25 kişilik sporcu grubu ile çalışılmıştır. Atıcılar ağırlık, uzunluk, vücut kütle indeksi, vücut yağ yüzdesi ve somatotip özelliklerine bakılarak test edilmiştir. Kadın ve erkekler atıcıların tümünde bu kriterlerin hepsine göre anlamlı farklılık tespit edilirken vücut tipleri arasında özellikler sınıflandırılmıştır (Aydın, Arıkan ve Revan, 2019).

Kocahan ve arkadaşları tarafından 2019 yılında yapılan çalışmada 12 kişilik milli takım oyuncusu ile çalışılmıştır. Sporcuların bir yıllık süredeki resmi karşılaşmalarda ayak basış genişlikleri, vücut salınımları ve kas grupları kuvvetleri ile atış performansları arasındaki ilişki incelenmiştir. Çalı̧̧manın sonucu olarak izometrik kas kuvvetinin performansta etkili olduğu, ayak açılıkları ve vücut salınım hızı arasında anlamlı ilişki bulunduğu tespit edilmiştir. Anlamlı ve etkisi büyük kas grupları için çeşitli antrenman önerileri geliştirilmiştir (Kocahan vd., 2019).

Tınaz tarafından 2019 yılında yapılan yüksek lisans tez çalışmasında 10 kişilik tabanca atış sporcusu ile çalışılmıştır. Göz takip cihazı ve atış simülatörü ile testler yapılmıştır. Çalı̧̧manın sonucunda tecrübesiz atıcılar olumsuz vuruş geri bildirimlerinden psikolojik olarak daha yüksek oranda etkilenmiş, tecrübeli atıcılarda ise bu oran daha alt seviyede kalmıştır (Tınaz, 2019).

Diler tarafından 2019 yılında yapılan yüksek lisans tez çalışmasında 20 kişilik sporcu grubu ile çalışılmıştır. Sporcuların karşılaşma öncesi tükettikleri kafein oranının kalp hızı, tetik düşürme süresi ve atış skorları üzerine etkisine bakılmıştır. Farklı cinsiyet grupları ve kafein kullanımından sonra farklı sürelerin geçmesiyle değişkenlik gösteren anlamlılıklar çeşitli istatistiksel testler ile elde edilmiştir (Diler, 2019).

Batur tarafından 2019 yılında yapılan yüksek lisans tez çalışmasında serbest zaman algısının yaş, cinsiyet, eğitim, medeni hal, gelir düzeyi gibi değişkenlere göre incelenmesi ele alınmıştır. Her kritere göre serbest zaman algısı durumu rakamları tespit edilerek anlamlılık yorumları yapılmıştır (Batur, 2019).

Muirhead ve arkadaşları tarafından 2019 yılında yapılan çalışmada ABD merkezli bir kolluk kuvveti grubu için zindelik durumu ile nişancılık ilişkisi incelenmiştir. 34 kişilik polis memuru ekibi için dört farklı kondisyon ölçümü ile üç farklı atış senaryosu üzerine çalışılmıştır. Çalışmada mekik, kavrama kuvveti ve bacak antrenmanları ile atıcılık arasında anlamlı bir ilişki olduğu gözlemlenmiştir (Muirhead vd., 2019).

Vural ve Okan tarafından 2021 yılında yapılan çalışmada 196 sporcu ile çalışılmıştır. Kişisel bilgiler ve sporda bilinçlilik ölçeği yardımıyla istatistiksel testler kullanılarak incelemeler gerçekleştirilmiştir. Sporcuların, spor yapma geçmişinin farkındalıkta baskın bir durumda olduğu cinsiyetin ise çeşitli düzeylerde farkındalık oluşturduğu tespit edilmiştir (Vural ve Okan, 2021).

Brown ve arkadaşları tarafından 2021 yılında yapılan çalışmada kavrama kuvvetleri ve atıcıların cinsiyetlerinin atıcılık performanslarına etkisi üzerine inceleme yapılmıştır. Etkili bir atış performansının büyük ölçüde kavrama gücüyle ilişkili olduğu düşüncesinden yola çıkılmıştır. Çalışmada 86 erkek ve 32 kadın atıı için lbs cinsinden el kavrama kuvvetleri tabanca yeterlilik puanları ile ölçülmüştür. Bu puanların yeterli kavrama düzeyi seviyesi için standartları belirlenmeye çalışılmışıtır. Atıcı cinsiyeti ile el kavrama kuvveti arasında anlamlı bir ilişki gözlemlenmiş̧ir (Brown vd., 2021). 


\section{Deney Tasarımı}

Atıcıların sahip oldukları özelliklere göre atışa olan elverişliliklerini belirleyebilmek için iki farklı ergonomik deney yapılmıştır. Yapılan bu iki deneydeki amaç testi en kısa sürede ve en az hata sayısı ile tamamlamaktır. Tasarlanan iki deney 55 farklı atıcıya uygulanmış ve deneyi tamamlama süreleri ile tamamladıklarında yaptıkları hata sayıları kayıt altına alınmıştır. Her deney sonrası atıcılara Kategori 1 ve Kategori 2 olarak adlandırılan 2 farklı kategoride atış yaptırılmış ve yaptıkları atış kayıtları başarılı veya başarısız olma durumlarına göre not edilmiştir. Kategori 1, dürbünlü silahla $200 \mathrm{~m}$ mesafedeki hedefe yapılan atış iken Kategori 2, uzun namlulu silahla 50 m uzaktaki hedefe yapılan atıştır. Bu çalışmada deneyleri en az hata sayısı ve en kısa süre ile tamamlayan atıcıların, silahlarını hedeflerinde daha uzun süre sabit tutacağı ve diğer atıcı rakiplerine göre daha başarılı atışlar yapacağ düşünülmüştür. Bu düşüncenin ortaya konması için deneylerden elde edilen sonuçlar ile atıcıların atış başarıları karşılaştırılmış ve aralarında anlamlı bir ilişki olup olmadığı ikili değişkenler (0-1, başarılı-başarısız vb.) ile tahmin yapmaya elverişli olan yöntemlerden lojistik regresyon analizi ile araştırılmıştır.

\subsection{Auto Scoring Mirror Tracer Test}

İlk deney, Auto Scoring Mirror Tracer ekipmanıyla yapılmıştır. Bu deney tek el ile yapılan ve atıcının bir hedefi aynadaki yansımasından görerek çizmeye çalıştığı bir şekilde tasarlanmıştır. Kullanılan test ekipmanı Şekil 1'de gösterilmiştir.

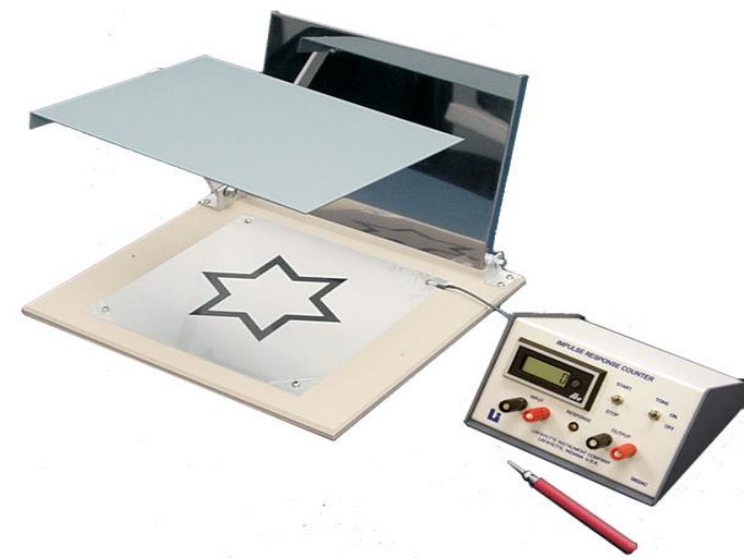

Şekil 1. Auto Scoring Mirror Tracer Test Ekipmanı

Deneyi yapan kişi aynadan gördüğü yıldız şeklini, desenin dışına çıkmadan en kısa sürede tamamlamaya çalışır. Deseninin dışına her temas edişinde hata sayacı 1 artar. Deneyi yapan kişi başladığı noktaya geri döndüğünde test biter ve tamamlama zamanı ile hata sayısı kayıt altına alınır. Deneyin uygulama aşamaları Şekil 2'de gösterilmiştir.

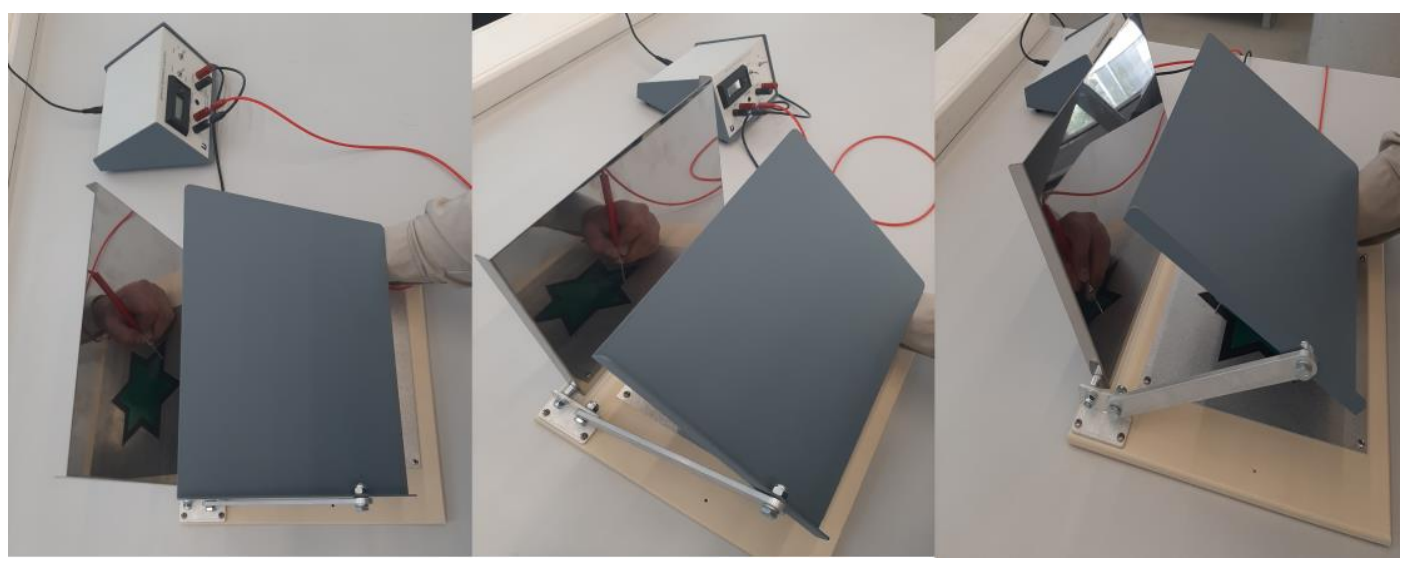

Şekil 2. Auto Scoring Mirror Tracer Test Uygulaması

Dürbünlü silahlarla uzaktaki hedeflere başarılı atış yapan atıcıların, bu testlerde en az hata ve en kısa zamanda başarılı olacakları düşünülmektedir. Çünkü yansıma testinde başarılı olan atıcılar, dürbünden atış yapacakları hareketli hedeflerin üzerinde daha uzun süre izleme ve takip yapabilecektir. Bu izlemenin sonucunda da başarılı atış oranları artacaktır.

\subsection{Two Arm Condition Test}

İkinci deney, Two Arm Coordination Test ekipmanıyla düzenlenmiştir. Bu deneyde ise atıcı iki el ile koordineli bir şekilde hedefi direkt olarak görerek çizmeye çalışmıştır. Kullanılan test ekipmanı Şekil 3’te gösterilmiştir. 


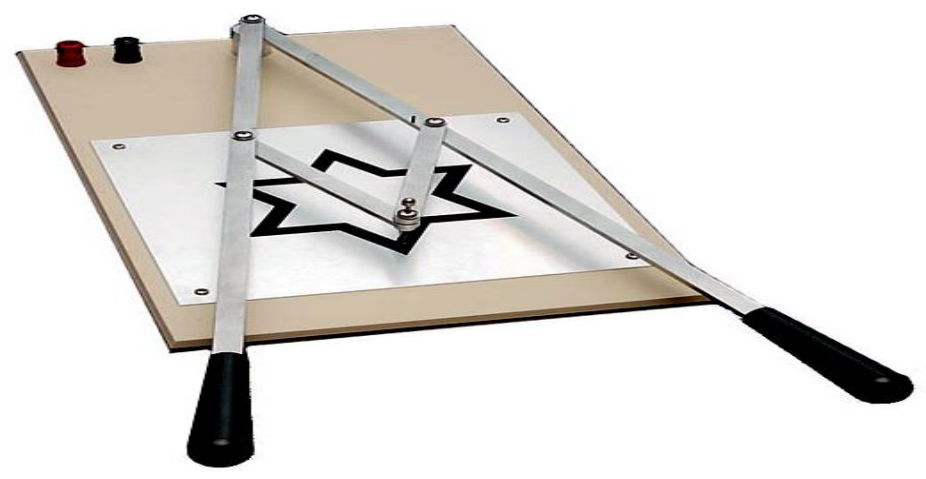

Şekil 3. Two Arm Condition Test Ekipmanı

Deneyi yapan kişi direkt olarak gördüğü yıldız şeklini iki elini koordineli bir şekilde kullanarak desenin dışına çıkmadan en kısa sürede tamamlamaya çalışır. Deseninin dışına her temas edişinde hata sayacı 1 artar. Deneyi yapan kişi başladığı noktaya geri döndüğünde test biter ve tamamlama zamanı ile hata sayısı kayıt altına alınır. Deneyin uygulama aşamaları Şekil 4'te gösterilmiştir.

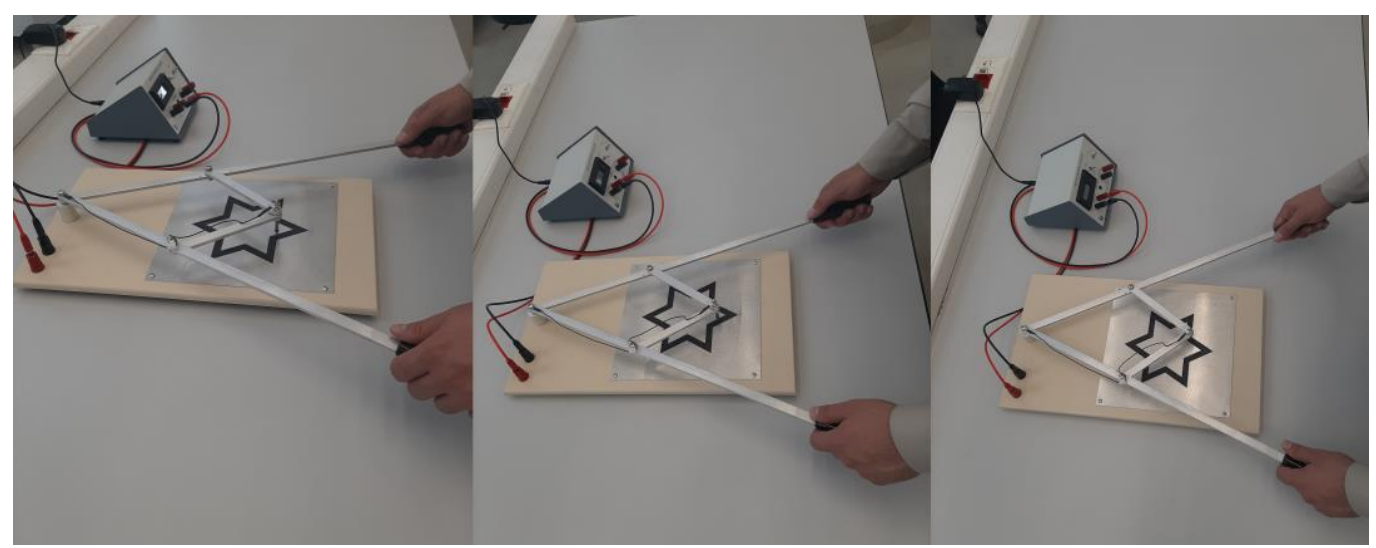

Şekil 4. Two Arm Condition Test Uygulaması

Tüfek gibi uzun namlulu silahlar ile hareketli hedeflere atı̧̧ yapan atıcıların, bu testlerde en az hata sayısı ve en kısa sürede başarılı olacakları düşünülmektedir. Çünkü bu tür koordinasyon testlerinde başarılı olan atıcıların, iki elleriyle hâkimiyetini sağladıkları silahlarını hedeflerin üzerinde daha uzun süre titremeden tutabilecekleri değerlendirilmektedir.

\subsection{Atış Testi}

Deneylerin uygulandığı 55 kişiye farklı kategorideki iki atış türünde test yapılmıştır. Kategori 1, dürbünlü silahla 200 metre ilerideki hedefe yapılan atış, Kategori 2 ise uzun namlulu silahla 50 metre ilerideki hareketli hedefe yapılan atıştır. Yapılan farklı kategorilerdeki atışlar Şekil 5’te gösterilmiştir.

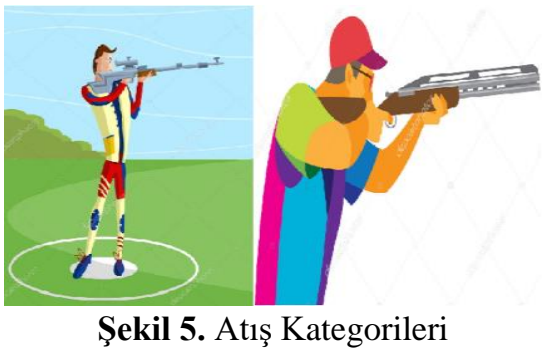

\subsection{Lojistik Regresyon Analizi}

Atıcıların deneyleri tamamlama süreleri ve hata sayıları ile atış başarıları ikili lojistik regresyon analizi ile incelenmiş ve aralarında anlamlı bir ilişki olup olmadığı araştırılmıştır.

Lojistik regresyon analizinde amaç, kategorik bağımlı değişkenin değerini tahmin etmek olduğundan, aslında burada yapılmaya çalışılan iki ya da daha fazla gruba ilişkin "üyelik" tahminidir. Buna göre analizin amaçlarından birinin sınıflandırma, diğerinin ise bağımlı ve bağımsız değişkenler arasındaki ilişkileri araştırmak olduğu ifade edilebilir (Mertler ve Vannatta, 2013).

Basit ve çoklu doğrusal regresyon analizleri, veri setlerinde bağımlı ve bağımsız değişkenler ile hata terimleri varyansının normal dağı̆lım göstermesi zorunluluğuna sahipken, lojistik regresyon analizi bu yöntemlerden farklı olarak bağımsız değişkenlerin dağılımına ilişkin karşılanması gereken herhangi bir zorunluluk içermez. Ayrıca bağımlı değişkenin ikili değer aldığı durumlarda da oldukça uygulanabilirdir (Tabachnick ve Fidell, 1996). 
Lojistik regresyonun yansız ve sapmasız istatistikler ortaya koyması için yeterli sayıda örneklem gerekmektedir. Özellikle bağımlı değişkenin ikiden fazla kategorisinin olduğu durumlarda, geçerli bir hipotez testi için en az 50 kişilik bir grup büyüklüğüne ihtiyaç vardır (Çokluk, 2010). Bu çalışmada da 55 farklı atıcı üzerinde testler uygulanarak bu koşul sağlanmıştır.

\section{Sonuçlar}

Auto Scoring Mirror Tracer (Deney 1) ve Two Arm Condition (Deney 2) testleri 55 farklı atıcıya uygulanmış ve Tablo 1'de gösterilen veriler elde edilmiştir.

Tablo 1. Deney 1 ve 2 Verileri

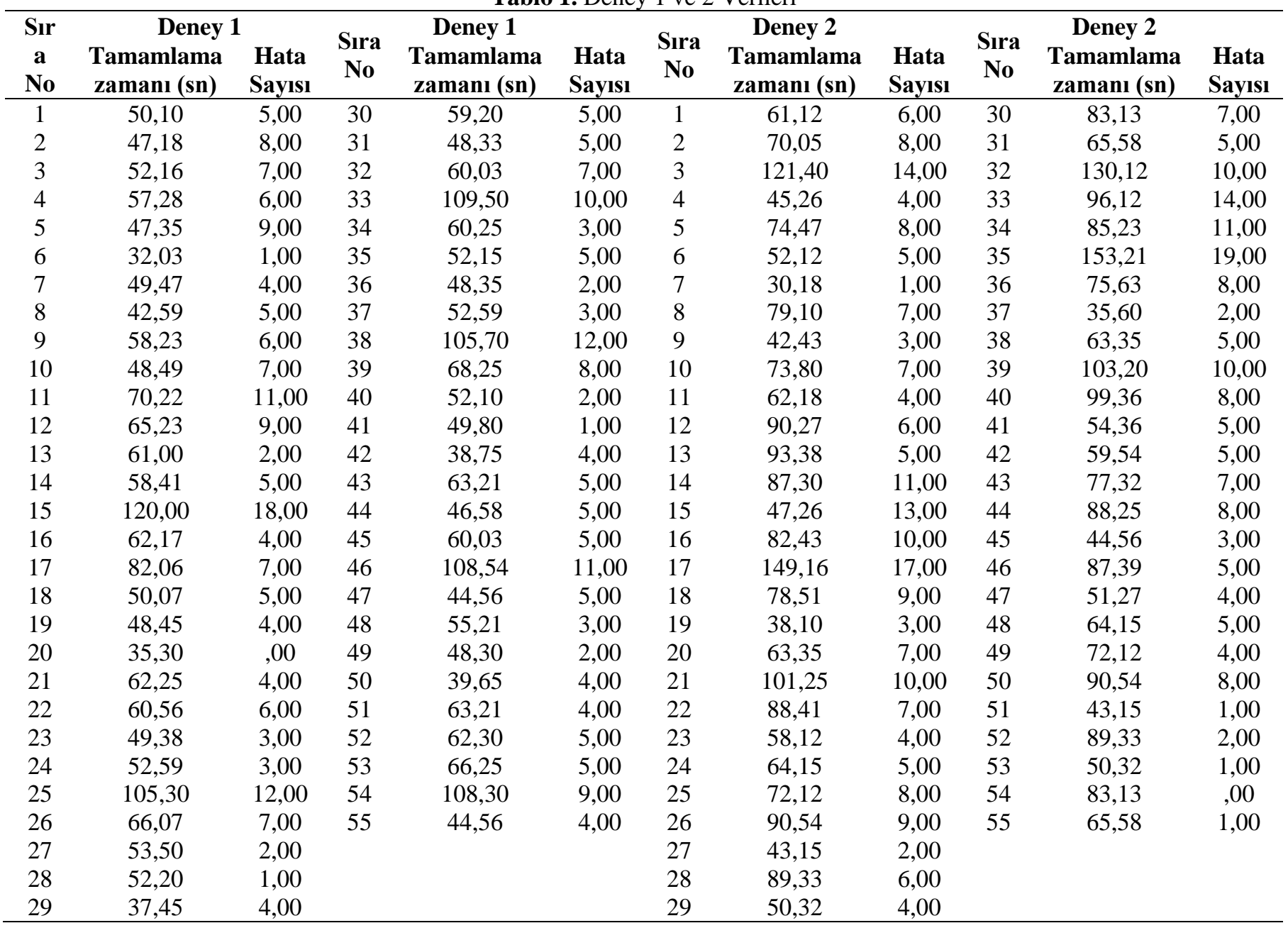

Uygulanan her deney sonrası atıcılara deneyin başarı ölçütü olacağı düşünülen kategorilerde atış yaptırılmış ve Tablo 2'deki atış kayıtları elde dilmiştir.

Tablo 2. Atış Kayıtları

\begin{tabular}{|c|c|c|c|c|c|c|c|}
\hline $\begin{array}{c}\text { Sira } \\
\text { No }\end{array}$ & Kategori 1 & Sira No & Kategori 1 & Sira No & Kategori 2 & Sira No & Kategori 2 \\
\hline 1 & Başarılı & 30 & Başarısız & 1 & Başarılı & 30 & Başarılı \\
\hline 2 & Başarısız & 31 & Başarılı & 2 & Başarısız & 31 & Başarılı \\
\hline 3 & Başarılı & 32 & Başarılı & 3 & Başarısız & 32 & Başarısız \\
\hline 4 & Başarılı & 33 & Başarısız & 4 & Başarılı & 33 & Başarısız \\
\hline 5 & Bașarısız & 34 & Başarılı & 5 & Bașarısız & 34 & Bașarısız \\
\hline 6 & Başarılı & 35 & Başarılı & 6 & Başarılı & 35 & Başarısız \\
\hline 7 & Başarılı & 36 & Başarılı & 7 & Başarılı & 36 & Başarısız \\
\hline
\end{tabular}




\begin{tabular}{|c|c|c|c|c|c|c|c|}
\hline 8 & Başarılı & 37 & Başarılı & 8 & Başarısız & 37 & Başarılı \\
\hline 9 & Başarılı & 38 & Başarısız & 9 & Başarılı & 38 & Başarılı \\
\hline 10 & Başarılı & 39 & Başarısız & 10 & Başarısız & 39 & Başarısız \\
\hline 11 & Başarısız & 40 & Başarılı & 11 & Başarılı & 40 & Başarılı \\
\hline 12 & Başarısız & 41 & Başarılı & 12 & Başarısız & 41 & Başarılı \\
\hline 13 & Başarılı & 42 & Başarılı & 13 & Başarısız & 42 & Başarılı \\
\hline 14 & Başarılı & 43 & Başarısız & 14 & Başarısız & 43 & Başarısız \\
\hline 15 & Başarısız & 44 & Başarılı & 15 & Başarısız & 44 & Başarısız \\
\hline 16 & Başarılı & 45 & Başarılı & 16 & Başarısız & 45 & Başarılı \\
\hline 17 & Başarısız & 46 & Başarısız & 17 & Başarısız & 46 & Başarısız \\
\hline 18 & Başarılı & 47 & Başarılı & 18 & Başarısız & 47 & Başarılı \\
\hline 19 & Başarılı & 48 & Başarılı & 19 & Başarılı & 48 & Başarılı \\
\hline 20 & Başarılı & 49 & Başarılı & 20 & Başarılı & 49 & Başarısız \\
\hline 21 & Başarılı & 50 & Başarılı & 21 & Başarısız & 50 & Başarısız \\
\hline 22 & Başarılı & 51 & Başarısız & 22 & Başarılı & 51 & Başarılı \\
\hline 23 & Başarılı & 52 & Başarılı & 23 & Başarılı & 52 & Başarılı \\
\hline 24 & Başarılı & 53 & Başarılı & 24 & Başarılı & 53 & Başarılı \\
\hline 25 & Başarısız & 54 & Başarısız & 25 & Başarısız & 54 & Başarılı \\
\hline 26 & Başarısız & 55 & Başarılı & 26 & Başarısız & 55 & Başarılı \\
\hline 27 & Başarılı & & & 27 & Başarılı & & \\
\hline 28 & Başarılı & & & 28 & Başarısız & & \\
\hline 29 & Başarılı & & & 29 & Başarılı & & \\
\hline
\end{tabular}

Elde edilen verileri anlamlandırmak için İkili Lojistik Regresyon Analizi yapılmıştır. Lojistik regresyon analizinde bağımlı değişken atış başarısı, bağımsız değişkenler ise deneyi tamamlama zamanı ve hata sayısı olarak tanımlanmıştır. Böylece elde edilecek modelde hata sayısı ve tamamlama zamanının kullanılmasıyla atış başarısı tahmin edilebilecektir. Tanımlanan bu değişkenler ve değerleri Tablo 3’te gösterilmiştir.

Tablo 3. Lojistik Regresyon Analizi Tanımlanan Değişkenler

\begin{tabular}{cc}
\hline Bă̆ımlı Değişken & Bağımsız Değişken \\
\hline $\mathrm{y}_{\mathrm{i}}=0$ Başarısız & $\mathrm{x}_{1}=$ Tamamlama zamanı \\
$\mathrm{y}_{\mathrm{i}}=1$ Başarılı & $\mathrm{x}_{2}=$ Hata Sayısı \\
\hline
\end{tabular}

\subsection{Auto Scoring Mirror Tracer Testi Analizi}

SPSS paket programı kullanılarak, ele alınan bağımsız değişkenler yardımıyla atış başarısı bağımlı değişkenini etkileyen değişkenleri belirlemek için İkili Lojistik Regresyon Modeli kurulmuştur. Öncelikle ileri doğru değişken seçme yöntemi ile etkili faktörler bulunarak lojistik regresyon denklemi elde edilmiş, sonra Omnibus testi ile bu denklemin genel anlamlılı̆ı incelenmiş ve son olarak Hosmer and Lemeshow ile Cox\&Snell and Nagelkerke testleri ile verilerin modele uygunluğu ve denklemin varyans açıklama gücü araştırılmıştır. İleri doğru değişken seçme tekniğiyle, lojistik regresyon analizi sonucu elde edilen en büyük olabilirlik katsayı kestirimleri Tablo 4'te verilmiştir.

Tablo 4. İleri Doğru Değişken Seçme Yöntemi Analiz Sonuçları

\begin{tabular}{ccccccccc}
\hline & \multirow{2}{*}{$\mathrm{B}$} & S.E. & Wald & df & Sig. & Exp(B) & \multicolumn{2}{c}{ 95\% C.I.for EXP(B) } \\
\hline hata & $-2,881$ & 1,333 & 4,671 & 1 &, 031 &, 056 &, 004 &, 765 \\
sure &,- 394 &, 202 & 3,786 & 1 &, 052 &, 675 &, 454 & 1,003 \\
hata by sure &, 030 &, 017 & 3,217 & 1 &, 073 & 1,031 &, 997 & 1,065 \\
Constant & 30,572 & 13,79 & 4,913 & 1 &, 027 & 0,125 & & \\
\hline
\end{tabular}

Tablo 4'teki significant değerlerine baktığımızda atış başarısındaki etkili faktörün sadece hata sayısı olduğu sonucu ortaya çıkmıştır. Çünkü significant değeri anlamlıdır $(\mathrm{p}<0,05)$. Tamamlama zamanı ve Hata sayısı * tamamlama zamanı etkileşimi değişkenleri ise anlamsız çıkmıştır. Dolayısıyla sınıflandırma için kullanılacak denklem Eşitlik 1'deki gibi oluşturulmuştur.

$\hat{y}=30,572-2,881 x_{1 i}-0,394 x_{2 i}+0,03 x_{12 i}$

Oluşturulan denklem 55 örneklem için test edildiğinde Tablo 5'de verilen sınıflandırma sonuçları elde edilmiştir. Ayrıntılı analiz verileri EK-A'da sunulmuştur.

Tablo 5. İleriye Doğru Değişken Seçme Tekniğine Göre Sınıflandırma Sonuçları

\begin{tabular}{ccccc}
\hline \multirow{2}{*}{ Gözlenen } & & Sonuç & Tahmin Edilen & \\
& & Başarısız & Başarılı & Doğruluk Yüzdesi \\
\hline \multirow{2}{*}{ Sonuç } & Başarısız & 10 & 6 & 62,5 \\
& Başarılı & 8 & 31 & 79,4
\end{tabular}


Kurulan model, 16 başarısız atışın 10'unu başarısız 6'sını ise başarılı olarak tahmin ederken, 39 başarılı atışın 31 'ini başarılı 8'ini ise başarısız olarak tahmin etmiştir. Buna göre modelin başarısızları doğru tahmin etme oranının \%62,5, başarılıları doğru tahmin etme oranının ise $\% 79,4$ olduğu tespit edilmiştir. Denklemin doğru sınıflandırma oranı ise \% 74,54 'dür. Bu durum modelin ele alınan atıcıların \%74,54'ünün atış başarı durumunu doğru olarak tahmin ettiğini göstermektedir Sonuç olarak, modelin atış başarısını tahmin etme gücünün iyi olduğu söylenebilir.

Modelin genel olarak anlamlılı̆̆ını incelemek için Omnibus testi uygulanmış ve elde edilen sonuçlar Tablo 6'da sunulmuştur.

Tablo 6. Model Katsayılarının Omnibus Test Sonuçları

\begin{tabular}{cccr}
\hline & Chi-square & df & Sig. \\
\hline Step & 44,558 & 3 &, 000 \\
Block & 44,558 & 3 &, 000 \\
Model & 44,558 & 3 &, 000 \\
\hline
\end{tabular}

Significant değerlerine bakıldığında modelin genel anlamlılı̆̆ının, yani uyum iyiliğinin istatistiksel olarak anlamlı olduğu görülmektedir $(\mathrm{p}<0,01)$.

Modelin verilere uygunluğunu araştırmak için Hosmer and Lemeshow testi yapılmış ve elde edilen sonuçlar Tablo 7'de verilmiştir.

Tablo 7. Hosmer and Lemeshow Test Sonuçları

\begin{tabular}{ccccc}
\hline Step & Chi-square & df & Sig. & 986 \\
\hline 1 & 1,381 & 7 & 986 \\
\hline
\end{tabular}

Hosmer ve Lemeshow testinin sonuçlarında Significant değerlerine bakıldığında tahmin edilen lojistik regresyon modelinin verilere uygun olduğu $(\mathrm{p}=0.986)$ görülmüştür.

Modelin varyansı açıklama gücünü ortaya koymak amacıyla Cox\&Snell ve Nagelkerke testi yapılmıştur. Elde edilen sonuçlar Tablo 8'de verilmiştir.

Tablo 8. Cox \& Snell ve Nagelkerke Test Sonuçları

\begin{tabular}{cccc}
\hline Step & -2 Log likelihood & Cox \& Snell R Square & Nagelkerke R Square \\
\hline 1 & $21,768^{\mathrm{a}}$ &, 255 &, 396 \\
\hline
\end{tabular}

Tablodaki sonuçlar incelendiğinde atış başarısındaki toplam varyansın \%39,6'sının, ele alınan bağımsız değişkenler tarafından açıklandığı tespit edilmiştir.

\subsection{Two Arm Condition Testi Analizi}

SPSS paket programı kullanılarak, ele alınan bağımsız değişkenler yardımıyla atış başarısı bağımlı değişkenini etkileyen değişkenleri belirlemek için İkili Lojistik Regresyon Modeli kurulmuştur. Öncelikle ileri doğru değişken seçme yöntemi ile etkili faktörler bulunarak lojistik regresyon denklemi elde edilmiş, sonra Omnibus testi ile bu denklemin genel anlamlılığı incelenmiş ve son olarak Hosmer and Lemeshow ile Cox\&Snell and Nagelkerke testleri ile verilerin modele uygunluğu ve denklemin varyans açıklama gücü araştırılmıştır. İleri doğru değişken seçme tekniğiyle, lojistik regresyon analizi sonucu elde edilen en büyük olabilirlik katsayı kestirimleri Tablo 9'da verilmiştir.

Tablo 9. İleri Doğru Değişken Seçme Yöntemi Analiz Sonuçları

\begin{tabular}{ccccccccc}
\hline & \multirow{2}{*}{$\mathrm{B}$} & S.E. & Wald & df & \multirow{2}{*}{ Sig. } & Exp(B) & \multicolumn{2}{c}{ 95\% C.I.for EXP(B) } \\
& & & & & & \multirow{2}{*}{ Lower } & Upper \\
\hline hata & $-1,776$ &, 717 & 6,143 & 1 &, 013 &, 169 &, 042 &, 690 \\
sure &,- 163 &, 068 & 5,788 & 1 &, 016 &, 850 &, 744 &, 970 \\
hata by sure &, 013 &, 007 & 3,769 & 1 &, 042 & 1,013 & 1,00 & 1,027 \\
Constant & 17,048 & 5,952 & 8,204 & 1 &, 004 & 0,625 & & \\
\hline
\end{tabular}

Tablo 9'daki significant değerleri incelendiğinde atış başarısındaki etkili faktörlerin; süre, hata sayısı ve hata sayısı * sure etkileşimi olduğu belirlenmiştir. Çünkü significant değerleri anlamlıdır $(p<0,05)$. Dolayısıyla sınıflandırmada kullanılacak denklem Eşitlik 2'deki gibi oluşturulmuştur.

$\hat{y}=17,048-1,776 x_{1 i}-0,163 x_{2 i}+0,013 x_{12 i}$

Oluşturulan denklem 55 örneklem için test edildiğinde Tablo 10'da verilen sınıflandırma sonuçları elde edilmiştir. Ayrıntılı analiz verileri EK-B'de sunulmuştur.

Tablo 10. İleriye Doğru Değişken Seçme Tekniğine Göre Sınıflandırma Sonuçları 
Gözlenen
Sonuç

Başarısız
26
3

Tahmin Edilen

Başarıl1
1
25

Doğruluk Yüzdesi

96,3

89,3

92,7

Kurulan model, 27 başarısız atışın 26'sını başarısız 1'ini ise başarılı olarak tahmin ederken, 28 başarılı atışın 25'ini başarılı 3'ünü ise başarısız olarak tahmin etmiştir. Buna göre modelin başarısızları doğru tahmin etme oranının \%96,3, başarılıları doğru tahmin etme oranının ise \%89,3 olduğu tespit edilmiştir. Denklemin doğru sınıflandırma oranı ise \%92,7'dir. Bu durum modelin ele alınan atıcıların \%92,7'sinin atış başarı durumunu doğru olarak tahmin ettiğini göstermektedir. Sınıflandırma oranına baktığımızda modelin atış başarısını tahmin etme gücünün oldukça yüksek olduğu değerlendirilmektedir.

Modelin genel olarak anlamlılı̆̆ını incelemek için Omnibus testi uygulanmış ve elde edilen sonuçlar Tablo 11'de sunulmuştur.

Tablo 11. Model Katsayılarının Omnibus Test Sonuçları

\begin{tabular}{cccr}
\hline & Chi-square & df & Sig. \\
\hline Step & 47,512 & 3 &, 000 \\
Block & 47,512 & 3 &, 000 \\
Model & 47,512 & 3 &, 000 \\
\hline
\end{tabular}

Tüm değişkenler modele ilave edildikten sonra, model uyum iyiliğini tespit etmek için significant değerlerine baktığında modelin genel anlamlılı̆̆ının, yani uyum iyiliğinin istatistiksel olarak anlamlı olduğu görülmektedir $(\mathrm{p}<0,01)$.

Modelin verilere uygunluğunu araştırmak için Hosmer and Lemeshow testi yapılmış ve elde edilen sonuçlar Tablo 12'de verilmiştir.

Tablo 12. Hosmer and Lemeshow Test Sonuçları

\begin{tabular}{cccc}
\hline Step & Chi-square & df & Sig. \\
\hline 1 & 4,889 & 7 &, 674 \\
\hline
\end{tabular}

Hosmer ve Lemeshow testinin sonuçlarında Significant değerlerine bakıldığında tahmin edilen lojistik regresyon modelinin verilere uygun olduğu $(\mathrm{p}=0.674)$ görülmüştür

Modelin varyansı açıklama gücünü ortaya koymak amacıyla Cox\&Snell ve Nagelkerke testi yapılmıştur. Elde edilen sonuçlar Tablo 13'te verilmiştir.

Tablo 13. Cox \& Snell ve Nagelkerke Test Sonuçları

\begin{tabular}{cccc}
\hline Step & -2 Log likelihood & Cox \& Snell R Square & Nagelkerke R Square \\
\hline 1 & $28,716^{\mathrm{a}}$ &, 578 &, 771 \\
\hline
\end{tabular}

Tablodaki sonuçlar incelendiğinde atış başarısındaki toplam varyansın \%77,1'inin, ele alınan bağımsız değişkenler tarafından açıklandı̆̆

\section{Tartışma}

Bu çalışmada, atıcılık sporuna ilgi duyan bireylerin eğitimi ve hali hazırda bu spor ile uğraşanların yarışma, müsabaka gibi faaliyetler için seçiminde yardımcı olması amacıyla yeni bir metot önerilmiştir. Bu eğitim ve seçim faaliyetleri için dürbünlü silah atışları ile tüfek gibi uzun namlulu silah atışları örnek olay olarak düşünülmüştür. Yapıları gereği bu olaylardaki başarıyı doğru tahmin edeceği öngörülen Auto Scoring Mirror Tracer ve Two Arm Condition testleri örneklem grubunda bulunan 55 sporcu ile yapılmıştır. Yapılan her test sonrası sporcuların hata sayıları ve testleri tamamlama süreleri kayıt altına alınmıştır. Atış başarıları ile kayıt altına alınan bu verilerin arasında anlamlı bir fark olup olmadığı ikili lojistik regresyon analizi ile araştırılmıştır.

Yapılan analiz sonucunda Auto Scoring Mirror Tracer testindeki hata sayısının dürbünlü silahlar ile yapılan atışlardaki sporcu başarısını etkileyen en önemli faktör olduğu tespit edilmiştir. Kurulan lojistik regresyon modelinin atış başarısını tahmin etme oranı \% 74,54 olarak bulunmuştur. Two Arm Condition testinde ise uzun namlulu silahlar ile yapılan atışlardaki sporcu başarılarının hata sayısına bağlı olduğu kadar testin tamamlanma süreleri ile de ilişkili olduğu görülmüştür. Bu test için kurulan lojistik regresyon modelinin atış başarısını tahmin etme oranı ise \%92,72 olarak hesaplanmıştır. Bu kapsamda her iki test için kurulan modellerin farklı kategorilerdeki atış başarısını ölçme gücünün yüksek olduğu sonucuna ulaşılmıştır. Dolayısıyla bu iki testin yeni sporcuların seçimi ve mevcut sporcuların eğitimi için uygulanabileceği değerlendirilmektedir.

Profesyonel anlamda bir spor dalı olan atıcılıkta başarı, çeşitli mesafelere ve çeşitli pozisyonlarda yapılan atışlar ile ölçülmektedir. Atıcılıkta hedefe odaklanma, temel vücut duruşu, el-kol ve omuz duruşları ile silahı tutarken ellerin koordinasyonu, silahı fazla baskı uygulayarak tutma veya gevşek olarak tutma gibi insan ergonomisi üzerinde etkili çeşitli ergonomik temel konularda hatalar yapılabilmektedir. El, kol ve omuz duruşları ile ellerin kullanımı ve koordinasyonu konuları ergonomi biliminin içerisinde var olan 
antropometrinin önemli bir ilgi alanına girmektedir. Çalışmada Auto Scoring Mirror Tracer ve Two Arm Condition ergonomi testlerinin atış başarısını doğru tahmin etmede ve ölçmede iyi sonuçlar verdiği ispatlanmış olan ergonomi testlerinin bu temel hataların giderilebilmesi amacıyla kullanılabileceği düşünülmektedir. Her iki ergonomik testte de sporcuların el ve kol ile hareket sınırları, titremeden hedef üzerinde sabit durabilme kabiliyeti ve iki elin birlikte koordinasyonu bu testler ile yapacağı antrenmanlar sayesinde geliştirilebilecektir. Bu testler sayesinde atıcı seçimi ve buna paralel müsabakalardaki başarı performanslarında artış sağlanabilecektir.

Gelecekte yapılacak çalışmalarda literatürdeki örneklerden de yola çıkılarak atıcıların fizyolojik, psikolojik ve biyolojik faktörleri de göz önünde bulundurarak modelde yer alan bağımsız değişkenlerin sayısı arttırılıp modelin kapsamı genişletilerek, testler için hata sayısı ve tamamlanma zamanı standartları belirlenerek sporcuların baskı altında gerçekleştireceği atış başarıların incelenebileceği ve bu testlerin tabanca atışı gibi atıcılık sporunun farklı branşları için atış başarısını tahmin etme yeteneğinin araştırılabileceği değerlendirilmektedir.

\section{EKLER}

EK A.

\begin{tabular}{|c|c|c|c|c|c|}
\hline No & hata & sure & tesonuc & Predicted probability & Predicted group \\
\hline 1 & 5,00 & 50,10 & başarılı & ,98174 & başarılı \\
\hline 3 & 7,00 & 52,16 & başarılı & ,70242 & başarılı \\
\hline 5 & 9,00 & 47,35 & başarısız & ,23592 & başarısız \\
\hline 6 & 1,00 & 32,03 & başarılı & 1,00000 & başarılı \\
\hline 7 & 4,00 & 49,47 & başarılı & ,99605 & başarılı \\
\hline 10 & 7,00 & 48,49 & başarılı & 82207 & başarılı \\
\hline 11 & 11,00 & 70,22 & başarısız & ,00398 & başarısız \\
\hline 12 & 9,00 & 65,23 & bașarısız & 03319 & bașarısız \\
\hline 13 & 2,00 & 61,00 & başarılı & ,98873 & başarılı \\
\hline 14 & 5,00 & 58,41 & başarılı & 87698 & başarılı \\
\hline 19 & 4,00 & 48,45 & başarılı & 99701 & başarılı \\
\hline 20 &, 00 & 35,30 & başarılı & 1,00000 & başarılı \\
\hline
\end{tabular}



4,00
52,59

105,70

68,25

52,10

49,80

38,75

63,21

46,58

60,03

108,54

44,56

55,21

48,30

39,65

63,21

62,30

66,25

108,30 44,56

\begin{tabular}{|c|c|}
\hline başarılı & ,88488 \\
\hline başarıl1 & ,59424 \\
\hline başarıl1 & 99904, \\
\hline başarıl1 & 99747 \\
\hline başarısız & 00059 \\
\hline bașarısız & 15622 \\
\hline başarıl1 & 99907, \\
\hline başarı111 & 99984 \\
\hline başarı111 & 99985 \\
\hline başarısız & ,85471 \\
\hline başarıl1 & 98805, \\
\hline başarı11 & ,35863 \\
\hline başarısız & ,00023 \\
\hline başarıl1 & 97479 \\
\hline başarıl1 & 97029 \\
\hline başarı111 & 99983 \\
\hline başarı111 & 99747 \\
\hline başarısız & 00058 \\
\hline başarısız & 05146 \\
\hline başarı11 & 99941 \\
\hline başarıl1 & 99993 \\
\hline başarıll & 99979, \\
\hline bașarısız & 68934 \\
\hline başarıl1 & 99216 \\
\hline başarıl1 & ,82781 \\
\hline başarısız & ,00036 \\
\hline başarı11 & 99519, \\
\hline başarı11 & 99442 \\
\hline başarıll & 99983 \\
\hline başarı11 & 99973 \\
\hline bașarısız & 85534 \\
\hline başarıl1 & ,73464 \\
\hline başarıl1 & ,51446 \\
\hline başarısız & 00017 \\
\hline basararll & 99897 \\
\hline
\end{tabular}

başarılı başarılı başarılı başarılı başarısız başarısız başarılı başarılı başarılı başarılı başarılı başarısız başarısız başarılı başarılı başarılı başarılı başarısız başarısız başarılı başarılı başarılı başarılı başarılı başarılı başarısız başarılı başarılı başarılı başarılı başarılı başarılı başarılı başarısız bașarılı

EK B.

\begin{tabular}{|c|c|c|c|c|c|}
\hline No & hata & sure & sonuc & Predicted probability & Predicted group \\
\hline 1 & 6,00 & 61,12 & başarılı &, 77944 & başarılı \\
\hline 2 & 8,00 & 70,05 & başarısız & 23171 & başarısız \\
\hline 3 & 14,00 & 121,40 & başarısız & 00524 & başarısız \\
\hline 5 & 8,00 & 74,47 & başarısız & 18948 & başarısız \\
\hline 6 & 5,00 & 52,12 & başarılı & ,95726 & başarılı \\
\hline 7 & 1,00 & 30,18 & başarılı & 99998 & başarılı \\
\hline 9 & 3,00 & 42,43 & başarılı & 99848 & başarılı \\
\hline 10 & 7,00 & 73,80 & başarısıı & 35249 & başarısız \\
\hline 11 & 4,00 & 62,18 & başarılı & ,95657 & başarılı \\
\hline 12 & 6,00 & 90,27 & başarısız & ,23446 & başarısız \\
\hline 13 & 5,00 & 93,38 & başarısız & 29012 & başarısız \\
\hline 14 & 11,00 & 87,30 & başarısız & 01662 & başarısız \\
\hline 19 & 3,00 & 38,10 & başarılı & 99911 & başarılı \\
\hline 20 & 7,00 & 63,35 & başarılı & ,53279 & başarılı \\
\hline 21 & 10,00 & 101,25 & başarısız & 02006 & başarısız \\
\hline 22 & 7,00 & 88,41 & başarılı & 16220 & başarısız \\
\hline 23 & 4,00 & 58,12 & başarılı & 97179 & başarılı \\
\hline
\end{tabular}




\begin{tabular}{|c|c|c|c|c|c|}
\hline 24 & 5,00 & 64,15 & başarılı & ,87454 & başarılı \\
\hline 25 & 8,00 & 72,12 & başarısız & ,21116 & başarısız \\
\hline 26 & 9,00 & 90,54 & başarısız & ,04898 & başarısız \\
\hline 27 & 2,00 & 43,15 & başarılı & 99950 & başarılı \\
\hline 28 & 6,00 & 89,33 & başarısız & ,24891 & başarısız \\
\hline 29 & 4,00 & 50,32 & başarılı & ,98786 & başarılı \\
\hline 30 & 7,00 & 83,13 & başarılı & ,21955 & başarısız \\
\hline 31 & 5,00 & 65,58 & başarılı &, 85850 & başarılı \\
\hline 32 & 10,00 & 130,12 & başarısız &, 00821 & başarısız \\
\hline 33 & 14,00 & 96,12 & başarısız & ,00307 & başarısız \\
\hline 34 & 11,00 & 85,23 & başarısız &, 01724 & başarısız \\
\hline 35 & 19,00 & 153,21 & bașarısız & ,03269 & başarısız \\
\hline 36 & 8,00 & 75,63 & başarısız & , 17943 & başarısız \\
\hline 37 & 2,00 & 35,60 & başarılı & ,99982 & başarılı \\
\hline 38 & 5,00 & 63,35 & bașarılı & ,88281 & başarılı \\
\hline 39 & 10,00 & 103,20 & başarısız & ,01890 & başarısız \\
\hline 40 & 8,00 & 99,36 & başarılı & ,05277 & bașarısız \\
\hline 41 & 5,00 & 54,36 & başarılı & ,94743 & başarılı \\
\hline 42 & 5,00 & 59,54 & başarılı & ,91599 & başarılı \\
\hline 43 & 7,00 & 77,32 & başarısız & ,29793 & başarısız \\
\hline 44 & 8,00 & 88,25 & başarısız & ,09557 & başarısız \\
\hline 45 & 3,00 & 44,56 & başarılı & ,99802 & başarılı \\
\hline 46 & 5,00 & 87,39 & bașarısız &, 42225 & bașarısız \\
\hline 47 & 4,00 & 51,27 & başarılı & ,98654 & başarılı \\
\hline 48 & 5,00 & 64,15 & başarılı &, 87454 & başarılı \\
\hline 49 & 4,00 & 72,12 & başarısız & ,88048 & başarılı \\
\hline 50 & 8,00 & 90,54 & başarısız &, 08476 & başarısız \\
\hline 51 & 1,00 & 43,15 & başarılı & ,99985 & başarılı \\
\hline 52 & 2,00 & 89,33 & başarılı & ,78686 & başarılı \\
\hline 53 & 1,00 & 50,32 & başarılı & 99957 & başarılı \\
\hline 54 & ,00 & 83,13 & bașarılı & ,97126 & başarılı \\
\hline 55 & 1,00 & 65,58 & başarılı & 99577 & başarılı \\
\hline
\end{tabular}

\section{Kaynaklar}

Aydın, A. S., Arıkan, Ş., \& Revan, S. (2019). Havalı Tabanca Atıcılarının Somatotip Özelliklerinin İncelenmesi. Gaziantep Üniversitesi Spor Bilimleri Dergisi, 4(2), 222-228.

Ball, K., Best, R., \& Wrigley, T. (2003). Body sway, aim point fluctuation and performance in rifle shooters: inter-and intraindividual analysis. Journal of sports sciences, 21(7), 559-566.

Batur, A. (2019). "Türkiye'de atııılık branşı ile ilgilenen sporcuların serbest zaman algısı ve engelleri", Yüksek Lisans Tezi, Batman Üniversitesi Sosyal Bilimler Enstitüsü, Batman.

Brown, A., Baldwin, S., Blaskovits, B., \& Bennell, C. (2021). Examining the impact of grip strength and officer gender on shooting performance. Applied Ergonomics, 97, 103536.

Carbone, P. D., Carlton, S. D., Stierli, M., \& Orr, R. M. (2014). The impact of load carriage on the marksmanship of the tactical police officer: a pilot study. J. Aust. Strength Cond, 22(2), 50-57.

Çokluk, Ö. (2010). Lojistik Regresyon Analizi: Kavram ve Uygulama. Educational Sciences: Theory \& Practice, 10(3).

Diler, K. (2019). "Havalı Tabanca Sporcularında Müsabaka Öncesi Tüketilen Kafeinin Kalp Atım Hızı, Tetik Düşürme Zamanı ve Atış Skoru Üzerine Etkisi", Yüksek Lisans Tezi, Ankara Yıldırım Beyazıt Üniversitesi Sağllk Bilimleri Enstitüsü, Ankara.

Erdoğan, M., Sağıroğlu, İ., Şenduran, F., Ada, M. \& Ateş, O. (2016). Elit Atıcıların El Kavrama Kuvveti ile Atış Performansları Arasındaki İlişkinin İncelenmesi. İstanbul Üniversitesi Spor Bilimleri Dergisi, 6(3), 22-30. 
Gilmore, R. (1976). " The New Courage": Rifles and Soldier Individualısm, 1876-1918. The Journal of Military History, 40(3), 97.

Kaya, M. (1999). Silah Ve Atış, Güvenlik Serisi-1, Ankara, 12-14.

Kayihan, G., Ersöz, G., Özkan, A., \& Koz, M. (2013). Relationship between efficiency of pistol shooting and selected physicalphysiological parameters of police. Policing: an international journal of police strategies \& management.

Kocahan, T., Akınoğlu, B., Genç, A., Kabak, B., Deliceoğlu, O. G., \& Hasanoğlu, O. A. (2019). Tabancalı Atıcılık Sporcularında Ayak Basış Genişliği, Postural Salınım, Üst Ekstremite İzometrik Kas Kuvveti ve Atış Performansı Arasındaki İlişkinin İncelenmesi. Turkiye Klinikleri Spor Bilimleri, 11(1).

Landman, A., Nieuwenhuys, A., \& Oudejans, R. R. (2016). The impact of personality traits and professional experience on police officers' shooting performance under pressure. Ergonomics, 59(7), 950-961.

Landman, A., Nieuwenhuys, A., \& Oudejans, R. R. (2016). Decision-related action orientation predicts police officers' shooting performance under pressure. Anxiety, Stress, \& Coping, 29(5), 570-579.

Morelli, F., Neugebauer, J. M., LaFiandra, M. E., Burcham, P., \& Gordon, C. T. (2014). Recoil measurement, mitigation techniques, and effects on small arms weapon design and marksmanship performance. IEEE Transactions on human-machine systems, 44(3), 422-428.

Muirhead, H., Orr, R., Schram, B., Kornhauser, C., Holmes, R., \& Dawes, J. J. (2019). The relationship between fitness and marksmanship in Police Officers. Safety, 5(3), 54.

Sivrikaya, K., \& Aydın, S. (2017). Elit atıcıların çoklu zekâ özelliklerinin cinsiyet, kullandıkları silah türü ve yaş faktörlerine göre karşılaştırılması. Ístanbul Aydın Üniversitesi Ĕgitim Fakültesi Dergisi, 3(2), 79-94.

Tenan, M. S., LaFiandra, M. E., \& Ortega, S. V. (2017). The effect of soldier marching, rucksack load, and heart rate on marksmanship. Human factors, 59(2), 259-267.

Tınaz, H. (2019). " Havalı Tabanca atıcılıkta Verilen vuruş Geribildiriminin göz Hareketleri Ve Performans üzerindeki Etkisi " Yüksek Lisans Tezi, Marmara Üniversitesi Să̆lık Bilimleri Enstitüsü, İstanbul.

Thomas, M., Pohl, M. B., Shapiro, R., Keeler, J., \& Abel, M. G. (2018). Effect of load carriage on tactical performance in special weapons and tactics operators. The Journal of Strength \& Conditioning Research, 32(2), 554-564.

Vannatta, R. A., \& Mertler, C. (2013). Advanced and multivariate statistical methods: Practical application and interpretation. Pyrczak Publishing, Los Angeles.

Vural, C., \& Okan, İ. (2021). Sporda Bilinçli Farkındalık: Atıcılık Spor Branşları Üzerine Bir Araştırma. Akdeniz Spor Bilimleri Dergisi, 4(2), 265-273. 